\title{
The Work Readiness of Master of Information Systems International Students at an Australian University: A Pilot Study
}

\author{
Dale Mackrell \\ Griffith Business School, Griffith University, Brisbane, Australia
}

\author{
d.mackrell@griffith.edu.au
}

\begin{abstract}
This paper reports on a qualitative pilot study which explores the attitudes and aspirations of international students in the Master of Information Systems (MIS) program at an Australian university. The findings are preliminary but suggest that the MIS program is an extrinsic motivator since it is used by students as a catalyst to change their future careers and lives. Furthermore, the students are appreciative of the MIS program's flexibility and the life-long learning initiative it encourages, as opposed to the more structured curricula in their countries of origin. While the findings indicate that the students approve overall the technical and business mix of courses in the MIS program, nevertheless, they are critical of the perceived lack of industry contact which would expose them to Australian social values and organisational cultures, thus preparing the students further for the workforce. This study makes a contribution as the basis of future research investigating the alignment between the academic preparation of MIS graduates and the industry expectations of technology intens ive organisations.
\end{abstract}

Keywords: Education, information systems, skills gap, alignment, Australia.

\section{Introduction}

A review of the literature from government, industry, and academic sources identifies that the Australian information and communication technology (ICT) industry suffers from spiralling low numbers of suitably skilled employees. Increasing ICT skills shortages in Australia has led to the immigration of overseas workers with the relevant skill sets to augment the supply. As well, the off-shoring and outsourcing of ICT work to other countries has exacerbated the problem for domestic students who perceive poor recruitment opportunities and ill-defined career paths, thus leading to a continuing decline of interest in IS education. To maintain enrolment levels in the wake of decreasing government funding, Australian universities are encouraging an increasing number of overseas students to enrol in postgraduate ICT programs such as the Masters of Information Systems (MIS).

Material published as part of this publication, either on-line or in print, is copyrighted by the Informing Science Institute. Permission to make digital or paper copy of part or all of these works for personal or classroom use is granted without fee provided that the copies are not made or distributed for profit or commercial advantage AND that copies 1) bear this notice in full and 2) give the full citation on the first page. It is permissible to abstract these works so long as credit is given. To copy in all other cases or to republish or to post on a server or to redistribute to lists requires specific permission and payment of a fee. Contact Publisher@InformingScience.org to request redistribution permission.

There is often confusion between the terms information technology (IT) and information systems (IS) both of which constitute ICT. According to Rose and Scheepers (2001, p.10), "information technologies may be understood as a material resource that supports information practice which in turn supports a wider set of social practices". Shanks, Hodgson and Darke (1996, p.1) define 
IS as being "concerned with the interaction between information technology, individuals, and organisations ... research in information systems has increasingly focussed on the social and organisational processes surrounding the introduction and use of information technology". The IS field is dynamic. Inevitably, changes in IS impact the education sector since graduates need to be employable.

This paper reports on a qualitative pilot case study which explores the views of Masters of Information Systems (MIS) students in the business school of an Australian university. The study seeks to determine whether the courses in the MIS program prepare students for the workforce, and in which areas the MIS program can be improved to produce more work-ready students. The study also endeavours to appreciate the perceptions of MIS students on the balance of technical skills and business processes in the courses of the MIS program and whether participation in the MIS program has changed the career and life aspirations of the students.

This study is expected to be the preliminary stage of more extensive research which consults with industry practitioners, academia, and a larger cohort of students. The project has the potential for several significant outcomes. There are benefits for the university as it aspires to lift both the enrolment in IS/IT education and the employment rate of IS/IT university graduates through assisting educators with more relevant curriculum design. There is the potential to increase the satisfaction and confidence of ICT graduates entering the workforce. Finally, there is a contribution to industry through the improved alignment between technical skills and business processes thus lessening the skills gap.

The structure of the paper is as follows. A review is provided of the relevant literature from government, industry, and academia. This is followed by an outline of the research strategy used and the conduct of the study. The findings section of the paper contains a discussion of the results of the study. In the conclusion section, the project is summarised, the findings are reflected upon and related back to the literature and the strategic plan of the university. Finally, topics for future research are proposed.

\section{Review of the Literature}

Recent studies from government, industry, and academia forebode a crisis in the ICT sector. In 2004-2005, according to the Australian Bureau of Statistics, ICT income was $\$ 87$ billion (DCITA, 2006). In a recent article in ComputerWorld (Bushell-Embling, 2007), Gary Nairn, the Special Minister of State for the Australian Government, acknow ledges the importance of addressing the skills shortage at the tertiary education level by issuing a challenge to government, industry, and educational institutions to work together to promote careers in ICT.

With the demand for ICT skills increasing, and enrolments in ICT programs at university dropping, there are calls for a new approach to marketing ICT careers (Foreshew, 2007). Along with predictions of dire skills shortages, the Australian Computer Society (ACS), the foremost association for ICT professionals in Australia, calls for a shift in strategic thinking from a technical skills focus to a more business oriented one. The ACS claims that Australia would be ideal as a global hub for innovative systems, business intelligence, risk management, and financial services. The ACS recommends working with the higher education sector to raise awareness of trends and opportunities (ACS, 2005).

The situation in Australia reflects that of other developed nations. In the USA, concerns over global ICT off-shoring and outsourcing, and low univers ity enrolments have resulted in a mismatch of skills supply and demand. With technical skills more likely to be externally sourced to foreign countries, the implications are a shift from the development and delivery of technologybased solutions to a demand for strong business and management skills for managing the ICT 
process. Consequently, the need for greater industry-educational collaboration is highlighted (Zweig et al., 2006).

Concerns regarding the gap between industry expectations and academic preparation have existed for some time (Lee, Trauth \& Farwell, 1995; Trauth, Farwell \& Lee, 1993) however the boundaries are changing. Recent research in this field suggests that a skills gap has been created through the mis-alignment of technological skills and business processes required by ICT employees in technology intensive organisations, compounded by the global issues referred to above (HP Technology, 2007; Kim, Hsu \& Stern, 2006). Kim, Hsu and Stern (2006, p.396) define the skills gap as "the disparity between the quality and adequacy of skills possessed by IS graduates and required by the IS/IT industry". Reportedly, IS/IT university graduates lack these requisite skills and are ill-equipped for the workforce (DCITA, 2006). Furthermore, these skills are poorly defined with a lack of understanding of the constructs associated with student learning in ICT (Jiang, Klein, Van Slyke, \& Cheney, 2003). Refer to Appendix A for a provisional list of technical skills and bus iness processes compiled by the author.

Standardised curricula have been developed for the education of students in the necessary skills and know ledge for ICT careers. One of these curriculum models is the MSIS 2006 which was developed by a joint task force of the Association for Information Systems (AIS) and the Association for Computing Machinery (ACM) to provide guidelines for graduate degree programs in IS (Gorgone, Gray, Stohr, Valacich, \& Wigand, 2006). The MSIS 2006 document refers to the 'sliding window' strategy which is the continuum of courses ranging from foundational to advanced. The purpose of this 'window' is to accommodate and support the varied backgrounds of the students and their career paths: consulting, data management, project management, software development, to name but a few (Gorgone et al., 2006, pp. 9-12).

Walsham (1993), a well-regarded IS theorist, in his authoritative book on computer-based IS in the contemporary world of the late twentieth century, develops a synthesised perspective on IS education compris ing both IT and management courses. Walsham criticises the lack of substantial theory on the human, social and ethical aspects of IS. In the section, 'Implications for Future IS Education', Walsham argues that the development of computer-based IS in enterprises requires more than technical expertise, and that IS professionals also need to have an understanding of organisations as well as social and cultural issues. While this book was written more than 15 years ago, the message is still current for IS practitioners, academics, and educationalists.

In summary, the ICT sector is booming but tertiary enrolments are declining or stagnating, aggravating the skills shortage. Furthermore, industry demands are moving from a technological to a business / managerial focus. This approach is supported by the literature which emphasises that, while technical training is essential for ICT students, the curriculum should expose students to the organisational and social aspects of managing computer-based information systems. In the next section, the research design and the conduct of the study are described.

\section{Research Strategy and Conduct of the Study}

It is well recognised that information systems research is multidisciplinary in nature with roots in applied psychology, computer science, economics, engineering, library science, linguistics, management science, mathematics, organisational behaviour and sociology, to name but a few and that information systems researchers increasingly appropriate theories from other disciplines (Rose \& Scheepers, 2001, p.6). This study was located within the disciplines of information systems, education, and sociology, and borrows theories from each. 
The qualitative tradition was developed for the social sciences, enabling researchers to study social, political, and cultural phenomena using more engaged and subjective data gathering methods than sanctioned under the functionalist tradition which is characterised by objectivism. Qualitative research methods are ethnography, action research, and case study research (Myers, 1997). Case study research was selected for the pilot study, enabling an interpretive, in-depth investigation into students in the MIS program. A qualitative research design was adopted with data gathered from a survey, followed by interviews with individual students. The following research questions elicted from the literature review represent the objectives of the study.

1. Do courses in the Master of Information Systems (MIS) program offer the right mix of technical and business skills?

2. How do students expect to use what they have learnt in the MIS program?

3. Does the MIS program adequately prepare students for the workplace?

4. If not, in which areas can the MIS program be improved?

5. Do the expectations of students change when studying for the MIS program?

All participants in the pilot study were international adult learners who had studied and worked outside of Australia and were enrolled in 2007 in the Masters of Information Systems (MIS) program in the business school of an Australian university, referred to as Z University in this paper. The course content of the MIS program was subject to minor variations depending on demand but included domain specific and generic skills as identified in Appendix A. A questionnaire was distributed to the students during a lecture in one of the courses of the MIS program. Twenty-five (25) students responded voluntarily to open-ended qualitative questions regarding the ir reasons for choosing the MIS program, the ir career aspirations, and the ir opinion on the balance of technical and bus iness courses in the program. In addition, there were some basic demographic, quantitative-style questions. Refer to Appendix B for the survey questions. Furthermore, there was an opportunity for each student to indicate willingness to be selected for an interview at a later date. The students were advised that every effort would be made to disguise their identity through the use of pseudonyms.

From the questionnaire responses, five students, from diverse backgrounds of culture, age and gender who indicated a willingness to be interviewed, were selected. The purpose was to interview as heterogeneous a group as possible. This is termed purposeful (purposive) sampling and is widely used to give balance and variety to a qualitative study. The selected students were later contacted by email with a request to interview them regarding the research project at a mutually agreed time and place. Each of the five interviews took between 20 to 50 minutes over a period of two weeks during the middle part of semester 2 in 2007 . This was deemed by the author to be the optimum timeslot: students had settled into their courses but they were not yet stressed by the end-of-semester workload. Refer to Appendix $C$ for the indicative interview questions. These questions served as a guide only since the interviews were semi-structured and the questioning flowed according to students' answers. This conversational approach to interviewing provided varied and often unanticipated responses. The interview data was later transcribed into Microsoft Word to enable the data to be analysed.

Table 1 below contains a summary of questionnaire and interview responses of study participants. This data formed the basis of the analysis process, enabling the author to categorise the information, particularly with regards to each participant's background, skills sought, chosen career path, and preferred assessment task in the MIS program. 
Table 1: Summary of survey and intervie w data for each participant

\begin{tabular}{|l|l|l|l|l|l|}
\hline Inter vie wee & $\begin{array}{l}\text { Country of } \\
\text { Origin }\end{array}$ & $\begin{array}{l}\text { Career Back- } \\
\text { ground } \\
\text { Rufus }\end{array}$ & $\begin{array}{l}\text { Career As pira- } \\
\text { India }\end{array}$ & $\begin{array}{l}\text { Skills } \\
\text { Sought }\end{array}$ & $\begin{array}{l}\text { Preferred } \\
\text { Assessment } \\
\text { Task }\end{array}$ \\
\hline Sally & India & $\begin{array}{l}\text { Science } \\
\text { (Technical) }\end{array}$ & Systems Analyst & Business & $\begin{array}{l}\text { Weekly As- } \\
\text { sessments } \\
\text { jects }\end{array}$ \\
\hline Jock & China & $\begin{array}{l}\text { Workplace } \\
\text { Health and } \\
\text { Safety } \\
\text { (Business) }\end{array}$ & IT Manager & Technical & $\begin{array}{l}\text { Reports / Re- } \\
\text { search }\end{array}$ \\
\hline Jed & Philippines & Business & Systems Analyst & Technical & Assignments \\
\hline Ken & India & $\begin{array}{l}\text { Engineering } \\
\text { (Technical) }\end{array}$ & IT Consulting & Business & - \\
\hline
\end{tabular}

Data analysis is widely regarded as an iterative process, beginning with the first data collected. Therefore, analysis of the early interviews helped shaped the course of the subsequent ones. Since no theoretical framework had been identified as an appropriate conceptual lens with which to analyse the interview data, a modified form of grounded theory was adopted (Glaser, 1998). This meant that the data was analysed and coded with an 'open mind' looking for underlying conceptual issues. Comparisons were made to compare themes in the data while memos were jotted in the margins. Since there were only five interviews, the data was hand-coded with the use of highlighters and pencils. Finally, emergent theories were applied to the literature as findings. Evidence from the findings is given as quotations by interviewees (using pseudonyms) in the next section.

\section{Findings and Discussion}

In this section, the analys is and interpretation of the data from the pilot study is discussed. From the analysis process, several themes emerged which addressed the research questions identified earlier as the objectives of the study. These themes are: 1) the balance of technical and business courses in the MIS program; 2) extrinsic motivation as a driver; 3) preferred assessment tasks; 4) lack of exposure to Australian industry; and 5) autonomous learning though greater control.

\section{Balance of Technical and Business Courses in the MIS Program}

As discussed above, extant government, industry, educational, and academic studies emphasise that ICT education needs to ensure that MIS graduates are equipped with an optimum balance of technical and business skills in order to reduce the current skills gap (Kim, Hsu \& Stern, 2006). The study offered the students an opportunity to express their opinions on the technical and business mix of courses in the MIS program and whether they considered the MIS adequately prepared them for the workforce. The responses to this theme were sourced from both the questionnaire and the interviews. In general, the replies of the students indicated that they rated very highly the balance of business / technical courses in the MIS program. It must be emphasised, however, that this study was not an evaluative tool per se and direct evaluation-style questions were not asked. 
Jock: Sofar the balance is very good - not too much business and not too technical.

Further questions revealed that the balance was important but whether a participant was looking for more technical or more business skills in the program depended on their background and the ir goals.

Ken: I like this course. Why I like it because I was purely from an engineering background. I came into consulting and there was a gap. In my opinion, there is more a lack of the management or the business view [in the MIS program].

Sally: My main concern is that I wanted to get into management not HR ... I looked at the universities on the coast and $Z$ was one of the options. They had an option of MIS. That's how I applied to Z University.

Rufus sought greater business skills since his background was technical. Nevertheless, he recognised the need to have both technical and business skills to be a successful manager in the ICT field.

Rufus: I was working on one of those projects, Ifelt the need to know about finance, accounting, economics and other business related information, cause with an engineering degree without a business background at all, it is very difficult to understand the finances involved and the other business procedures and practices involved.

Cause I've worked in a technical industry being a technical analyst, I think that unless you have that technical knowledge whatever you do in management is not going to help at all. Unless you are very good at the fundamentals in your technical field, you wouldn't be able to manage a lot of people.

However not all students were satisfied with the MIS program offerings. Jed was pre-occupied with the technical deficiencies of the MIS program from his perspective.

Author: How would you get a better outcome from the MIS program?

Jed: I think it is only by doing the technical side. I was expecting that I would learn also ... having no technical experience at all, that is right in my mind ...I have hired a personal tutor.

Overall, the participants in the study were aware that to work in industry, a balance of technical and business skills was essential. Each student had assessed their existing skills levels, the study programs available to them, and had deliberately chosen to study for the MIS program. The MIS program was identified as a means of filling the technical and business gap and opening future opportunities to them.

\section{Extrinsic Motivation as a Driver}

In the context of effective teaching and learning in the higher education sector, Biggs (2003) a theorist in the education field, explains that motivation (extrinsic, social, achievement, intrins ic) is a driver of teaching / learning through cognitive engagement. Biggs (2003, p.61) defines extrinsic motivation as "when students are motivated ... because of the value or importance they attach to what the outcome brings". Biggs goes on to explain that the focus of the student is not so much on the process of learning but on obtaining the reward (or punishment). This concept is important for understanding the attitudes of international students undertaking the MIS program.

The students in the study had incentives to succeed in the MIS program. They perceived the MIS qualification as a means of equipping themselves with the skills to be able to change their careers or their lives. Jock's experience was from the regimented Chinese work context. He explained that in China, work is very stressful with a cultural expectation that you remain at your desk for 
long hours by starting work early and leaving late. Jock claimed that this was due to the massive Chinese population and the fear that employees could be readily replaced at work unless work commitment was demonstrated.

Jock: Yes basically because of the environment, the culture, we must do that [work long hours]. If you don't do that, it is easy to find another people to replace you in that position so the competition is very fierce in China.

I don't have time with my family [in China]. I want to change my life. After I am more qualified, I can be made to be more hired [hireable] or manage the job more flexibly.

While Rufus was motivated by less desperate circumstances, studying for the MIS was associated with his career goals.

Author: Do you think doing the MIS will change the way you see your future?

Rufus: The main reason I am doing the MIS is to keep in mind my short term goal and long term goal. Eventually I want to be in a managerial role. It might change over a period of time but I think I will keep in touch with what I am learning out here.

It was apparent that the students were eager to alter the course of their work careers or their living circumstances and they perceived the MIS qualification as the driver to achieve this transformation.

\section{Preferred Assessment Tasks}

In the context of effective higher education teaching and learning, Biggs (2003) considers types of assessment and their purposes. In this study, the students identified assessment tasks which would increase their engagement with the courses in the MIS program. Refer to Table 1 for the preferred assessment task of each student.

Sally: Well, one is weekly assessment would help. Maybe notfor heavy marks but for lesser marks since it keeps you on your toes. Maybe one or two courses which can have weekly assessment.

Jock: I think report format is good because to do report assessment, we need to read a lot of journal articles and solve the problem. That will be a good way and we can learn best practice from these other studies... case studies, real-world projects ....

Jock mentioned the use of case studies to provide an insight into Australian bus inesses as a best practice. By and large, the students seemed to view assessment tasks as an opportunity to fortify their study commitment and to improve their learning outcomes.

\section{Lack of Australian Industry Exposure}

The importance of MIS graduates being readily employable has been discussed. The students reflected critically on areas where the MIS program could better prepare students for the workforce. One omission in the MIS program, which was recognised by the majority of participants, was the lack of exposure to Australian business and the culture within Australian organisations.

Jock: Industry practice and case studies will be helpful.

Rufus: I wanted a little more introduction of what happens in industry itself. So that there is a balance of the theory with the practical. Being from India which is so different.... 
Sally: I think the industry approach is something. Theoretically we are learning a lot but practically we are not using the knowledge we get. It would be great if we could work in industry and do things out there then be in the class and do projects....

Aside from providing international students with an insight into the Australian way of managing a business, the students recognised the need to learn more in a practical sense about Australian organisations beyond the theory taught in the classroom.

\section{Learning Autonomously}

In the MSIS 2006 document, Gorgone et al. (2006) refer to the diverse backgrounds and career goals of students and its impact on course selection. Similarly, students in the study sought variable educational outcomes. While this topic was not directly related to the research objectives, nevertheless the responses were very instructive. Two participants readily revealed that they had experienced extremely structured systems of education in their countries of origin compared with Australia.

Rufus explained the restrictive education regime in India. He was concerned that students in India were compelled to enrol in subjects (courses) and prepare assessments even when reluctant to do so. In the MIS program at Z University, while there are mandatory core courses and compulsory assessments, there are also electives which students can select according to the ir needs. Moreover, these courses can be undertaken in a range of sequences. As a consequence, the cohort of students changes every semester encouraging motivation through change and variety.

Rufus: After being here, there's one basic difference that I see is that there it is a more an enforced way of teaching [in India], cause, as a professor, they make sure that you study, they'll catch you for not doing your assignment or for not work ing out the homework problems that they have provided us or for not attending class and the whole idea is to make you want to study. Even if you kind of don't want to do that subject, you'll be eventually forced to do it.

And it doesn't give you that amount of choice. If you are doing an MBA, it has structure like four subjects that you have to do this semester and another four the next semester, and you can't pick and choose which ones you want to do this semester and which ones you want to do the next and there's like a class of 60 people and the first year you will be together, the second the same group of 60 people will still be together, and the third the same group will still be together. Yes, it is very different from out here.

And the way I am being taught our here is more a kind of self-learning so I think I'll continue doing this.

Rufus identified that a deterministic educational approach reduces the empowerment of students and the capacity for life-long learning. Sally had a similar experience with the education system in India. Her major concern was that students had reduced flexibility in their courses and little incentive to explore intellectually outside the parameters set by faculty.

Sally: In India, it is very competitive but on the other hand, they spoon-feed you. Postgraduate students are given information and they say, $O K$, this is what you need to know. And you may not know something outside of the book.

The study participants demonstrated the capacity for critical thinking in many and various ways as evident in the interview extracts already provided. Each participant analysed past experiences and self-assessed their strengths and weaknesses. The participants recognised through critical reflection that as MIS students in Australia, they had more control over the courses they studied 
but they were expected to be independent thinkers. The question of whether the participants expected as MIS graduates to be adequately prepared for the workforce was summed up by Ken.

Ken: I'll be much more confident.

The opportunity to learn autonomously appealed to the students.

\section{Conclusion}

This qualitative pilot case study explored the attitudes and aims of international students undertaking the MIS program in the business school of an Australian university. As well, the study explored the skills and know ledge that MIS students expected to acquire from their tertiary learning and whether the MIS program prepares the students adequately for the workplace. In the conclusion section, the main findings of the study are recapped within the scope and objectives of the study. As well, the study contributions, limitations, and suggestions of directions for future research are provided.

All partic ipants identified the emphasis on technical skills and/or business processes which they sought in the MIS program. The findings suggested that most participants were satisfied with the technical and business balance in the MIS program although there were indications that students seeking more technical courses preferred a stronger technical concentration while students seeking business and management outcomes preferred a stronger business and management focus.

The findings also suggested that the career and/or life experiences of students in their countries of origin motivated them to attain the MIS qualification. This finding is aligned with Biggs (2003) who identifies extrinsic motivation as related to task outcomes.

Jed was a special case. He was studying at the university on a government scholarship and had very specific technical demands for the job to which he will be assigned in his home country on his return. Consequently, because of his limited technical background, Jed had sought additional academic support from a tutor. Jed's case may accentuate the value of the 'sliding window' strategy proposed in the MSIS 2006 document where courses are offered on a continuum ranging from foundational to advanced (Gorgone et al., 2006). Limited resources in the MIS program may prohibit operationalising such as strategy but the notion is worthy of consideration.

The study revealed a major defic iency in the MIS program. Study participants identified that courses in the MIS program lacked exposure to Australian industry. As a consequence, this has hindered the understanding of Australian social values and organisational cultures by the students. This is a perspective supported by Walsham (1993) who argues that ICT professionals require more than technical expertise, and that ICT professionals also need to have an understanding of organisations and associated social and cultural issues before they are work-ready. While the MIS program does offer an Applied Project course and an Internship, this fact seems to be underrated by the students.

The university in question is promoting work-integrated learning (WIL) as a valuable learning experience. For the purposes of the university's strategic plan, the university (2007) defines WIL as "... educational activities that integrate theoretical learning with its application in the workplace. These educational activities should provide a meaningful experience of the workplace application that is intentional, organised and recognised by the institution, in order to secure learning outcomes for students that are both transferable and applied." Improving the alignment between theoretical learning and practical know-how through work-integrated learning (WIL) will benefit students, educational institutions, and industry by producing work-ready graduates.

It was recently reported in Campus Review (Fannin, 2007, p.8) that international students require 12 months relevant and practical experience in their chosen occupation to support their tertiary qualifications in order to be eligible for permanent residency (PR). While the study did not ex- 
plore this topic, if PR is the goal of the study participants, it is arguably not the responsibility of the tertiary institution to provide industry exposure but that of the student. This issue is outs ide the scope of the study but is worthy of consideration.

The study also identified that most of the participants were aware of and were appreciative of the less restrictive and more flexible university and workforce environments that exist in Australia compared with their countries of origin. In general, the partic ipants recognised that greater personal control and independence have the potential to transform the ir study and work lives through enhancing and empowering the ir learning and careers. The emotional outcome was increased satisfaction and confidence. Furthermore, it was evident that many of the participants were developing a capacity to think critically and reflectively, described as transformational learning by Harvey and Knight (1996). This augurs well for the ir ability to respond effectively to future study and/or work challenges.

The scope of this study has been small and therefore the findings are preliminary. Inevitably, there are aspects of the topic which have not been investigated in any depth. The following topics could be recommended as the basis for future research.

1. Explore further the industry needs of MIS students and attempt to match with existing courses in the MIS program such as an Applied Project course, an Internship course, and work-integrated learning (WIL) as supported by the university

2. Identify the technical and business skills that constitute the skills gap.

3. Increase participation in the study by including another cohort of students as well as industry and faculty participants to triangulate the data.

4. Include an evaluation on the quality of the study using Kle in and Myers (1999) seven principles as well as a discussion of triangulation for rigour and relevance.

In summary, the preliminary findings suggest that the MIS program is a catalyst enabling students to alter the direction of their careers and lives. Furthermore, the students are appreciative of the MIS program's flexibility and approve the technical and business mix of courses in the MIS program. Nevertheless, the students are critical of the perceived lack of industry contact which would enable them to apply the theory learnt at university to real-world practice. It is proposed that work-integrated learning (WIL), an Internship, or an Applied Project course would expose the students to Australian social values and organisational cultures making the students more prepared for the workforce.

Assisting educators with more relevant curriculum design benefits the university in its goal to increase the employment rate of university graduates as outlined in the strategic plan. As well, the satisfaction and confidence of MIS graduates entering the workforce is expected to increase. Lastly, there is a contribution to industry through the improved alignment between technical skills and business processes thus lessening the existing ICT skills gap.

\section{References}

ACS. (2005). Policy statement on onshoring ICT based analytics. Australian Computer Society. Retrieved $21^{\text {st }}$ October 2007 from http://www.acs.org.au/acs policies/docs/2005/onshoringpolicysep05.pdf

Biggs, J. (2003). Teaching for quality learning at university. Berkshire: The Society for Research into Higher Education \& Open University Press.

Bushell-Embling, D. (2007). ICT economy booming but where's the talent? Forget min ing, ICT a major contributor to productivity, ComputerWorld, Retrieved $10^{\text {th }}$ January 2008 from http://www.cio.com.au/article/189091/ict economy booming where talent?fp=4\&fpid=1941

DCITA. (2006). Building Australian ICT skills: Report of the ICT skills foresighting working group. Australian Govern ment, Department of Communications, Information Technology and the Arts, March. 
Fannin, P. (2007). Skilled migration changes set to alter courses demand. Campus Review, 17(40), 8.

Foreshew, J. (2007, November 13). No graduate relief for tech skills squeeze: Offshoring contributes to an impression that there's no career for Aussies in IT. The Australian IT, p.31.

Glaser, B. (1998). Doing grounded theory. Mill Valley CA: Sociology Press.

Gorgone, J., Gray, P., Stohr, E., Valacich, J., \& Wigand, R. (2006). MSIS 2006: Model curricu lu m and guidelines for graduate degree programs in information systems. Communications of the Association for Information Systems, 17.

Harvey, L., \& Knight, P. (1996). Transforming higher education. Buckingham: The Society for Research into Higher Education \& Open Un iversity Press.

HP Technology. (2007). Ten tips to get business and IT talking. Retrieved 8th June 2007 from http://h71028.www7.hp.co m/eNe wsletter/cache/461816-0-0-0-121.ht ml

Jiang, J., Kle in, G., Van Slyke, C., \& Cheney, P. (2003). A note on interpersonal and communication skills for IS professionals: Evidence of positive influence. Decision Sciences, 34(4), 799-812.

Kim, Y., Hsu, J., \& Stern, M. (2006). An update on the IS/IT skills gap. Journal of Information Systems Education, 17(4), 395-402.

Kle in, H. K., \& Myers, M. D. (1999). A set of principles for conducting and evaluating interpretative field studies in information systems. MIS Quarterly, 23(1), 67-93.

Lee, D., Trauth, E., \& Farwell, D. (1995). Critical skills and knowledge requirements of IS professionals: A joint academic/industry investigation. MIS Quarterly, September, 313-340.

Myers, M. (1997). Qualitative research in information systems. MIS Quarterly, 21(2), 241-242.

Rose, J., \& Scheepers R. (2001). Structuration theory and information systems development - Frame works for practice. Proceedings of the 9th European Conference on Information Systems (ECIS), Bled, Slovenia.

Shanks, G., Hodgson, B., \& Darke, P. (1996). The use of structuration theory in information systems research. Proceedings of the 7th Australasian Conference on Information Systems (ACIS), Hobart, Tasmania.

Trauth, E., Farwell, D., \& Lee, D. (1993). The IS expectation gap: Industry expectations versus academic preparation, MIS Quarterly, September, 293-307.

Walsham, G. (1993). Interpreting information systems in organizations. England: John Wiley \& Sons

Z University (2007). Definition of work-integrated learning. Retrieved 20th Nove mber 2007 from http://www62.gu.edu.au/policylibrary.nsf/mainsearch/a0d60f04626b7f144a2571800063dd56?opendoc $\underline{\text { ument }}$

Zweig, P., Kaiser, K., Beath, C., Bullen, C., Gallagher, K., Goles, T., Howland, J., \& Simon, J. (2006). The information technology workforce: Trends and implications 2005-2008. MIS Quarterly Executive, $5(2)$. 


\section{Appendix A: Glossary of Relevant Terms}

The skills listed here are presented within the categories of domain specific, generic transferable skills, and transformational learning, as outlined by Harvey and Knight (1996, p.122). The skills list has been adapted to be applicable to the IS/IT sector of industry. The list is only a guide and not exhaustive.

\section{Domain or Discipline Specific:}

Technical skills include database knowledge (SQL, Oracle etc), programming languages (VB .Net, Java, C++ etc), and network architecture (.NET framework, CGI etc). These are taught in information technology (IT) faculties and, to a lesser degree, in information systems (IS). The technical but more 'managerial' skills are associated with systems analys is and design, project management, business intelligence, and IS/IT policy and governance. These topics are taught in IT and IS schools.

Business processes include the know ledge of managerial practices, finance, economics, employment relations, workplace health and safety, organisational culture, human resources, and legal studies. Some of these topics would be available in an MBA program.

\section{Gene ric or transfe rable skills:}

These skills include problem solving, communication (oral, written and interpersonal), group and collaborative work skills, research skills, and ethics. These are not always emphasised in IS/IT schools but may be offered.

\section{Transformational learning:}

These skills relate to learning at a higher level and are based on Harvey and Knight (1996, p.12). They include:

- Independence as a learner

- Commitment to life-long learning, especially through reflection

- Recognition that existing frames of reference both empower and limit

- Development of critical dia lectical thinking

\section{Appendix B: Survey Questions}

The following questions are optional. You may ans wer all, some or none.

Your willingness to participate in this survey is indicated by the completion of the survey and the return of this page to the researcher.

1. Explain your choice of a career for when you graduate.

2. Why did you select the Master of Information Systems (MIS) program at this university?

3. How do you find the balance of 'technical' and 'business' content in the MIS program?

\section{Personal Characteristics:}

Name: Student Number:

Country of Origin: 
What is your age?

Under 25

25-45

45-65

65+Age $\square$

What is your gender?

Male

Female

$\mathrm{Y} / \mathrm{N}$

Are you willing to participate in an interview of 30-45 minutes at a later date?

Signature:

Date:

Thank you for your participation

\section{Appendix C: Indicative Interview Questions}

1. How will you use what you have learnt in the Master of Information (MIS) program?

2. In what areas do you feel prepared to be an information systems (IS) professional?

3. In what areas do you feel you need more preparation to be an IS professional?

4. How have your expectations of the MIS program changed, if at all?

5. How has the MIS program changed your career choice, if at all?

Thank you for your participation

\section{Biography}

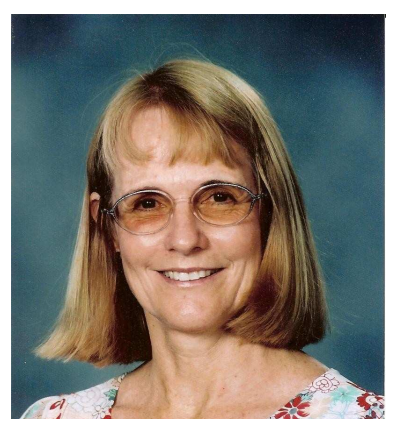

Dale Mackrell, $\mathrm{PhD}$, is a lecturer in Information Systems in the Griffith Business School of Griffith University, Brisbane, Australia. Her research interests are business intelligence, in particular, the adoption and use of agricultural decision support systems, gender and technology, as well as the alignment between the academic preparation of MIS graduates and the industry expectations of technology intensive organisations. Dale is an early career researcher who has published several conference and journal papers. 